This item was submitted to Loughborough's Research Repository by the author.

Items in Figshare are protected by copyright, with all rights reserved, unless otherwise indicated.

\title{
An investigation of professional top-level youth football coaches' questioning practice
}

PLEASE CITE THE PUBLISHED VERSION

http://dx.doi.org/DOI:10.1080/2159676X.2016.1157829

\section{PUBLISHER}

(c) Taylor \& Francis

\section{VERSION}

AM (Accepted Manuscript)

\section{PUBLISHER STATEMENT}

This work is made available according to the conditions of the Creative Commons Attribution-NonCommercialNoDerivatives 4.0 International (CC BY-NC-ND 4.0) licence. Full details of this licence are available at: https://creativecommons.org/licenses/by-nc-nd/4.0/

\section{LICENCE}

CC BY-NC-ND 4.0

\section{REPOSITORY RECORD}

Cope, Ed, Mark Partington, Christopher J. Cushion, and Stephen Harvey. 2019. "An Investigation of Professional Top-level Youth Football Coaches' Questioning Practice”. figshare.

https://hdl.handle.net/2134/20731. 


\section{An Investigation of Professional Top-Level Youth Football Coaches' Questioning}

2 Practice

3 Ed Cope $^{\mathrm{a}}$, Mark Partington ${ }^{\mathrm{b}}$, Christopher J. Cushion ${ }^{\mathrm{c}}$ and Stephen Harvey ${ }^{\mathrm{d}}$

$4{ }^{a}$ Department of Sport, Health and Exercise Science, University of Hull, Hull, UK,; ${ }^{b}$

5 Department of Sport and Physical Activity, Edge Hill University, Ormskirk, UK; ${ }^{c}$

6 School of Sport, Exercise and Health Sciences, Loughborough University,

7 Loughborough, UK; ${ }^{d}$ College of Physical Activity and Sport Sciences, West Virginia

8 Unversity, USA

10 To position learners as more central components in the coaching process, scholars suggested that

11 coaches should employ a questioning approach, which may lead to the development of desirable learner outcomes (i.e., increased problem solving and decision-making skills) studies, however, indicate that coaches rarely employ questions within their practice. When questions are asked, these questions rarely move beyond lower-order or 'fact seeking' enquiries. While this research provides information concerning the frequency and in some cases, the type of questions coaches asks, it fails to report the more discursive nature of coaches' questioning approaches. In order to address such limitations, the purpose of this study was to investigate Coach Questioning Practices (CQPs). We recorded the practices of five academy youth level football coaches' subjected the data to a conversation analysis (CA), This enabled the analysis of interaction between coach and player(s). Findings revealed that CQPs, regardless of coach or context followed similar discursive patterns. In particular, three themes presented themselves in each CQP: 1) coaches' requirements for an immediate player response, 2) leading questions for a desired response, 3) monologist nature of coach/player interaction. This showed that the coach positioned themselves as the gatekeeper of knowledge and learners as passive recipients. This reinforces the messages from previous work that has suggested coaches' ideologies inform their practice, and are stable structures that are difficult to change. We concur with other researchers that there is a need for further investigation in this area to better understand how dominant discourse can be challenged. 
Cope et al.

\section{Introduction}

It has been acknowledged that effective coaching positions learners as active agents, or co-learners in the learning process (e.g. Becker 2009; Cushion 2013; Kidman 2005). For this to be realized in practice requires a shift in how coaches conceptualize their role within the coaching process (Light and Evans 2010). Traditionally, coaches have been found to use high levels of instructional behaviours (e.g. Cushion and Jones, 2001; Potrac et al. 2007), that limit learners' input (Ford et al. 2010) positioning them as passive recipients of learning. For coaches to include learners in the learning process they need to move away from using such high levels of instructional behaviours toward the use of questioning (Davis and Sumara, 2003; Kidman, 2005). For example, through coaches using questions they are able to engage their players in dialogue and discussion (McNeill et al. 2008) that in turn enables them to more critically reflect on their performance (Forrest 2014). Furthermore, asking questions potentially develops players problem solving, decision-making, and creative thinking skills, as well as their game understanding (Chambers and Vickers 2006; Wright and Forrest 2007).

Research in coaching from observation studies have shown that coaches, regardless of sport or coaching context, ask players few questions (e.g. Becker and Wrisberg 2008; Cushion and Jones 2001; Potrac et al. 2007, inter-alia). These studies reveal that coach questioning is a small proportion of their coaching behaviour typically between 2-5\% of overall reported coaching behaviours. More recent studies, inclusive of wider definitions of 'questions', demonstrated coaches predominantly asking convergent rather than divergent questions (e.g. Harvey et al. 2014; Partington and Cushion 2013). Convergent and divergent questioning develops conditional knowledge (Ennis 1994) of “'when, why and under what conditions declarative and procedural knowledge should be used” (p.165); divergent questioning is seen as pivotal in learning to develop higher order thinking. So, questioning is a pedagogic tool that appears rarely employed by coaches, and even when it is, evidence would suggest that the questioning approach fails to cognitively engage players.

Beyond reporting frequency in systematic observation studies, there is limited evidence of how coaches employ questioning approaches in their practice. Interviewing coaches about their behaviours and practice has been a popular method, and while providing insight to why coaches use certain behaviours and practices over 
others, coaches' perceptions alone cannot be relied upon to give objective accounts of coaching practice (Partington and Cushion 2013). Therefore, the purpose of this study is to investigate the ways in which top-level youth coaches used questioning in their practice. The study looks to extend previous studies in coaching that have captured only the frequency and the nature (i.e. convergent or divergent questions) of coaches' questioning - and largely not considered the players response or the conversational nature of such coaching moments. To this end we aimed to capture the questionresponse exchange that occurs between coach and players and describe this as coach questioning practice (CQP).

Given that coaching can be recognised as an educational and pedagogical endeavour (Jones, 2006) and the limited research that explores coaches' questioning approach, educational research offers a lens to examine the appropriateness of coach questioning to meet desired outcomes (e.g. problem solving, decision-making, opportunities to reflect on performance). For example, research suggests that teachers formulate the majority of questions, with these being more fact-seeking in nature, rather than requiring students to think beyond the recall of information (i.e. a small number of higher order questions) (e.g. McNeill et al. 2008; Pedrosa-de-Jesus and Da Silva Lopes 2011). This questioning structure has been identified as initiation, response and evaluation (IRE) (Cazden 2001). Topic or task related sets of IRE are the most common discursive patterns reported in educational settings, including physical education (Cazden 2001; Wright and Forrest 2007). Metzler (2000) argues that lower order, fact seeking questions, which are characteristics of IRE require "less knowledge and ability for making responses" than higher order questions that "build on the knowledge from the lower-order" (p.108) and engage "analysis, synthesis and evaluations skills” to generate new knowledge (p.107).

A number of assumptions and issues arise from these findings that require further exploration when thinking about coaching. First, there is an assumption that the level of question and type of cognitive processing required is fixed and can be generalized independently of the subjects and their context (Yang 2006). The players' (learner) experience and cognitive characteristics, the content and purpose of the question, and the relevance and meaningfulness of the content to the player will all impact on their learning (Pagliaro 2011). Moreover, questioning practices are subjective interactions that involve a range of complementary pedagogic behaviours, 
Cope et al.

such as body language, giving time for answers, encouraging or discouraging of learner contribution, and discussion (Pedrosa-de-Jesus and Da Silva Lopes 2011).

This suggests that, to understand more about the nature of CQP questioning cannot be reduced to frequency and cognitive level alone, but instead needs to be considered as rooted in coaches' and athletes' differing knowledge, concepts and ideological beliefs about coaching and learning (Pedrosa-de-Jesus and Da Silva Lopes 2011; Prain and Hicky 1995; Yang 2006) - thus recognising that coaches' understanding of learning, their assumptions and beliefs, and their ontological and epistemological underpinnings acting often implicitly, informs their practice (cf. Cushion 2013; Light 2008). In addition, there are recognizable and traditional discursive practices in coaching; rules, conventions, and dispositions that control coaching that are based on "tradition, circumstance and external authority" (Tinning 1988, p.82; Harvey et al. 2010). Thus, the internal relationship between conceptions of coaching and learning will impact how coaches perceive the functionality of questions and the degree to which they understand and apply this approach to their pedagogy (e.g. Cushion 2013; Harvey et al. 2010; Light and Evans 2010; Partington and Cushion 2013; Pedrosa-de-Jesus and Da Silva Lopes 2011). Therefore, an analysis of CQP is also a useful indicator of underlying assumptions, beliefs and conceptions of coaching and learning. However, analyzing coach interactions as routine patterns of communication does not interrogate fully the ideological determinants and outcomes of these patterns (Prain and Hickey 1995). There remains an ideological aspect to coaching where discursive practice involves power, and control of when, where and by whom (Cushion and Jones 2006; Potrac et al. 2007) not least in CQP - where ideological beliefs can act to "negatively influence and retard the perspectives” (Crum 1993, p.344). This lends further weight to the need for in-depth qualitative examination of coach questioning beyond its 'type' and 'frequency'. Therefore analysis of CQP offers a way to describe and interpret practice at the micro level of coaching interactions, while also providing insight to ideological influences in terms of coach assumptions and suppositions - thus providing a deeper analysis of coaching's discursive patterns.

In this case, qualitative conversational analysis (CA) offers a useful tool to interpret coach-player interactive patterns (Groom et al. 2012) and allows a broader consideration of CQP beyond behavioural data about 'frequency' and 'type'. CA was 
131 pertinent as CQPs were characterised as 'conversations' as coach and player 132 undertook a process of 'turn-taking' (Gréhaigne et al. 2005). Therefore, this method 133 allows consideration of how interaction is initiated, how individuals earn the right to 134 speak, the degree of freedom individuals have in what they say, how often individuals 135 speak and how communication is controlled (Prain and Hickey 1995). Considering 136 CQP in this light provides interesting insight into the discursive practice and 137 conceptual orientation of their interrelationship - as well as description of the learning 138 environment being created. So far, research into questioning has lacked empirical 139 evidence from in situ or 'natural' coaching environments. For example, Wright and 140 Forrest (2007) and Forrest (2014) provided examples of the qualitative nature and 141 dialogue that occurs between teacher/coach and learners/players when different types 142 of questions are asked. However, these studies 'manufactured' questioning practices 143 to show the types of questions a practitioner could ask, and subsequent learner 144 responses, reporting only half the story and leaving the relationship between 145 conceptions of practice and learning, and actual practices unclear. Therefore, there is 146 a limited appreciation of the contextualised and situated nature of questions asked by 147 coaches, and, crucially, the responses given by players that create particular learning 148 environments.

\section{Methodology}

\section{Study Context}

151 The study was set inside a professional English youth football academy. In England, 152 academy clubs are the place where youth players identified as talented are nurtured 153 with the aim to prepare them for full-time professional football. The Premier League 154 operates the academy system with each academy required to implement the 155 'developmental pathway of players' (The Premier League Elite Player Performance 156 Plan 2011). The developmental pathway is comprised of three distinct phases; the 157 foundation phase, the youth development phase, and the professional development 158 phase. The foundation phase is from under 9's to under 11's, the youth development 159 phase is from under 12's to under 16's, and the final phase, the professional 160 development phase is from under 17's to under 21's (The Premier League Elite Player 161 Performance Plan 2011). The participants in this study coached players from under 16210 's to under 14's crossing both foundation and youth development phases. 
Cope et al.

163 Foundation phase players are provided with between 5 and 8 hours of coaching and

164 weekend competitive matches each week, increasing to between 12 and 16 hours in 165 the youth development phase.

\section{Participants}

167 Participants were five male academy football coaches who were homogeneously 168 sampled, which is a type of purposive sampling that investigates the practices of those 169 who have shared similar contextual experiences. All coaches were required by the 170 club to have attained the Football Association (F.A.) level 3 (UEFA B) and a full F.A.

171 Youth Award. The following section provides an overview of further qualifications 172 and characteristics specific to each of the five coaches involved in the study. All 173 names used are pseudonyms.

174 Tom

175 Tom was 32 years of age at the time of study and coached the under 10's. Tom had 176 four years coaching experience in this setting and another eight years professional 177 coaching on Fundamental skills at participation level. He had a postgraduate level 178 education in strength and conditioning, and a Post Graduate Certificate in Education.

181 Will was 36 at the time of study and coached the under 12's. He had been coaching 182 for 12 years of which 4 have been spent in this setting. Will left school at 16 and 183 therefore had no formal higher educational qualification beyond those he had in 184 football.

Oliver

187 Oliver was 28 at the time of study and coached the under 14's. He had ten years coaching experience of which five years was in the current setting. He had a postgraduate level qualification in sports coaching and a Post Graduate Certificate in

190 Education.

192 Joe

193 Joe was 26 at the time of study and coached the under 11's with Paul in an official 194 equal role. This meant that both were responsible for designing and delivering 
Cope et al.

195

196

197

198

199

200

201

202

203

204

205

206

207

208

209

210

211

212

213

214

215

216

217

218

219

220

practice, and matters regarding team selection. Joe had four years coaching experience all in this setting. Joe had a degree level qualification.

\section{Paul}

Paul was 45 at the time of study and coached the under 11's. He had eleven years coaching experience, three years in the current setting and six years at two other professional football clubs in youth development. His qualifications included a degree level qualification, and a Post Graduate Certificate in Education.

\section{Data collection and procedure}

To enable qualitative analysis of CQPs, three practice sessions for each coach were video recorded during the middle of the football season (fifteen in total). Video recording each session allowed for more detailed analysis, as it enabled each session to be reviewed an infinite number of times. Three sessions enabled an accurate representation of the coaches’ practice (Brewer and Jones 2002). In total 1215 number of minutes of coaching was recorded with each session lasting on average 81 minutes. Broken down, Tom was recorded coaching for 239 minutes, Will for 248 minutes, Oliver for 231 minutes, Joe for 252 minutes, and Paul for 245 minutes. CQPs were distributed relatively evenly amongst the coaches, with Tom initiating 44 CQPs, Will 52, Oliver 46, and Joe and Paul 53 each.

Post-observation field notes were used to enable us to report on matters linked to the CQPs, and the coaches' wider discursive practices. For example, what was the purpose of the session, what activities were undertaken, what was the nature of coachathlete interactions? Specific to questioning for example, why did the coach initiate the CQP, who was the intended recipient of the questioning? It was determined that a CQP occurred when there were any form of a questioning-response exchange between coach and player(s). So, this could have been limited to only one question followed by one response with only one player, or equally it could have been a series of questions followed by responses from a from a number of players within that particular CQP before the coach engaged in some other form of intervention (i.e. instruction or feedback). In this sense, CQPs varied in time (six seconds - one minute 32 seconds) and length (one question and one response - thirteen questions and ten responses). 
Cope et al.

228

229

230

231

232

233

234

235

236

237

238

239

240

241

242

243

244

245

246

247

248

249

250

251

252

253

254

255

256

\section{Data analysis - conversational analysis}

To appreciate, and maintain the complexity of coach-player interactions through the CQPs, a CA approach was employed. CA reveals interactions 'as they are' (Groom et al. 2012, p. 230), as the concern is not only with what has been said, but also how it was said (Hepburn and Bolden 2013). This was vitally important in the context of this study, to not only understand the frequency and type of questioning, but also coaches’ complementary pedagogic behaviour and discursive patterns, including for example how they asked questions, and the time they gave athletes to respond that contributed towards the learning environment constructed. Furthermore, CA was an appropriate approach to use in the context of this study, given its focus on in-situ recordings of the coach/player interaction (Mondada 2013). Indeed, given the connected nature of interaction between coach, player and environment Groom et al. (2012) advocate CA as a powerful analytical device to further understand sports coaching.

The CA analysis followed the procedures and transcription symbols offered by Groom et al. (2014) (see table 1). Two members of the research team reviewed the recorded sessions independently. Initially, two complete reviews of each session were undertaken. In the first review each CQP was transcribed. This included the question initiation, the sequence of questions asked and responses given. The focus of the second review was the lead in to the question and how the questions were asked including notes of the coaches' wider discursive practice. This included such things as the tone of the coaches' voice, the extent to which players were being encouraged to respond to questions, and how coaches reacted when players failed to answer a question. To ensure the credibility of the data, two further reviews were undertaken by the same two members of the research team (Hastie and Hay 2012) as well as peerdebriefing sessions (Patton 2002). This ensured researcher reflexivity through discussing the separate analysis (Miles and Huberman 1994). Where differences did occur in the analysis, the same two research members reviewed the video again before reaching a point of confirmability (Harvey et al. 2015).

\section{Results}

Insert table 1 here of conversational analysis symbols 
Cope et al.

258

259

260

261

262

263

264

265

266

267

268

269

270

271

272

273

274

275

276

277

In total 248 CQPs were subjected to CA. This represented 158 minutes out of 1215 minutes of the coaches total practice time, which equated to approximately $13 \%$ of their overall time being spent on questioning. The data are presented in the form of CQPs or 'vignettes' enabled by the employment of a CA approach that include detail from the notes taken during the coach observations. Presenting data in this way reveals the complex nature of social interactions and the micro-reality of coaching practice (Jones 2009), and also retains the authentic nature in which questions were asked.

On reviewing the CQP data, which included the contextual information, a number of themes were identified. These were: 1) coaches' requirements for an immediate player response; 2) leading questions for a desired player response, and 3) monologist nature of coach/player interaction. However, these themes were not particular to certain CQPs, but rather occurred within CQPs. For example, it was not the case that theme one occurred in 40 CQPs, or theme two occurred in 50 CQPs. Rather, these themes appeared to give some structure to all of the CQPs, regardless of the number of questions and responses, or the lead up to, and purpose of the questioning. So, there was limited variability in the CQPs, with each following similar patterns, regardless of coach or session. For the purposes of this study, and to better present and understand the data, we present a CQP and link it to each of the three themes. We then offer a general discussion, which connects data with theory.

\section{Coaches' requirements for an immediate player response}

CQP 1

The session has been running for an hour. The coach stops the practice and shouts for all of the players to come to him. The coach had already stopped the players on eight previous occasions to give feedback/instruction e.g. "There needs to be greater intensity in some of your movements off the ball”, as well as providing feedback and instruction while the players were practicing e.g. "move faster", "get that ball in an be positive". The players gather around the coach, who stands quietly waiting for all the players to listen .

Coach: What did we start off with (.)

Player: $=$ Footwork and $::$ movement 

Player: When you've got the ball look around you and give accurate passes ${ }^{\circ}$ Coach: = What did we move onto then (.) when we put another red in, what was the decision we had to make (1.2)

Player: Make it quicker ::

Coach: What was the passing then (1.4)

Player: $\underline{\text { Harder, }}$ longer passes

Coach: $=$ Did you find that easier then (2.1)

Player: \{I didn't because it was a smaller area and it was four vs. three

While this period of questioning was directed to the whole group, the players were not required to cluster around the coach. Instead, players had 'frozen' on the spot at the point at which the coach stopped practice. Players were dispersed within the playing area. At this point in the questioning episode, which had been going on for approximately 20 seconds, six of the players' have turned to what is going on in other sessions that are going on at the same time. However, as the coach directs his questioning to only those responding, he does not notice some of the players not paying attention.

Coach: Was it chaos all the time (1.4)

Player: Yes, but organised chaos

313 Data highlighted that coaches often required players to provide immediate responses 314 to questions they had asked. In this CQP, players were rarely given more than two 
Cope et al.

315 seconds (e.g. 'What did the lads in the bibs do all the time (0.7)') to provide a 316 response to a question. This indicated that players perhaps knew the answer that their 317 coach wanted to hear as a consequence of instruction provided by the coach earlier in 318 the session. When responses were not immediate, coaches often acted to fill in the 319 players' silence (e.g. '= What did we move onto then (.) when we put another red in, 320 what was the decision we had to make (1.2)'). In many instances, the coaches used

321 self-answering and rhetorical questions where players had little time to think about 322 their responses.

323 Questions that promote critical thinking require player's to consider a number 324 of responses before selecting an answer they feel to be most appropriate (Daniel and 325 Bergmann-Drewe 1998; Wright and Forrest 2007). However, for players to be able to 326 consider their responses, rather than expecting immediate responses, coaches need to 327 allow time for reflection (McNeill et al. 2008), as well as allow players the 328 opportunity to discuss answers amongst themselves. Wiersema and Licklider (2009) 329 talk about the need to provide opportunities for learners to ask questions of 330 themselves and others as this results in greater levels of learning; to think and reflect 331 more deeply about their performance.

332 Time is required for critical thinking and reflection to happen (Chambers and 333 Vickers 2006). The CA showed that coaches in this case rarely provided players with 334 time to think about their responses. As already discussed, when an immediate 335 response was not forthcoming, coaches filled the silence with an answer or re-initiated 336 through a re-phrased question. McNeill et al. (2008) argues that inexperience tends to 337 produce too many questions in quick succession, and this does not allow time to 338 reflect on possible answers and their consequences - while the coaches in this case 339 cannot be described as 'inexperienced' it could be argued that their experience of a 340 less directive and more questioning approach was limited. Indeed, research has 341 indicated that coaches are unable to facilitate well or conduct instructional 342 conversations, not knowing how, having never experienced sufficient guidance, nor 343 seen effective models in action (Cushion 2013; Light and Evans 2010; Partington and 344 Cushion 2013).

345 Leading questions for a desired response

$346 \quad C Q P 2$ 
Players are engaging in a modified game after waiting for 4 minutes while the coach explained how he wanted the activity to run, and the players role. Just over 3 minutes into this activity the coach stops practice after seeing one of the players perform exactly how he had instructed them to

Player: $<\underline{\text { Moved }>}$

Coach: SO if he comes in this way what might you three do :: (0.8)

Silence, the players stand and stare at the coach failing to give a response. The coach responds to the silence by immediately re-phrasing the question.

Player: > Waited for the defender $<$

Coach: So when he waits for the defender, $<$ what is it harder for that defender to do $>(4.4)$

The coach has his hands out in front of him, as he looks at every player waiting for an answer to be given but no players respond; they stare at the coach. The coach continues to look around the group waiting for a response from someone. When it doesn't come the coach re-phrases the question. or harder for him< (0.8)

Player: $\underline{\text { Harder }}$

Coach: (.)WHY

Player: ${ }^{\circ}$ Because he has to run over to chase the ball ${ }^{\circ}$

Coach: So when he is running across what do you need to 
Cope et al.

Player: - Run across to support him.

This CQP shows how a number of the coach's questions were 're-initiation' i.e. re-phrased questions when there was no response or not the desired response to a question. For example, in this CQP the coach asked 'Okay, so what did you do $\uparrow$ (5.1)'. When players failed to provide a response the coach rephrased the question to 'SO what have they done to help him (1.2)', which a player was then able to offer a quick response. This is synonymous with an IRE questioning framework where the coaches' asked 'test' questions to illicit a predetermined 'correct' response (Wright and Forrest 2007). Cazden (2001) notes that this predictable routine can easily become 'recitations' rather than genuine discussion, or verbal interaction with the development of new understanding. Data also showed that coaches prolonged the final word of some of their questions or there was a rise in intonation ('SO if he comes in this way what might you three do :: (0.8)'), meaning players were being led to a certain response. When this occurred, the players' gave much quicker responses ('>Waited for the defender<') as they appeared to more clearly understand the response the coach wanted to hear. Thus, the frequency of questioning appeared relatively high when coaches adopt this approach 'real' interaction and hence potential for learning was actually limited (Harvey and Light 2015).

In most cases, the CQP failed to move beyond recall or leading in nature, requiring players to produce an answer from memory (Siedentop and Tannehill 2000). Thus, the verbal role of the players was not generative and individual interpretation was not encouraged. However, analysing the data using a CA approach revealed a greater detail of information concerning how coaches structured the CQP. For example, where players were unsure of their response, their answer was delivered in a much softer tone (' ${ }^{\circ} \mathrm{Get}$ out of the way') than when they were confident they were giving an answer they believed their coach wanted to hear.

\section{Monologist nature of coach/player interaction} part of the practice is a conditioned game and has been running for just over two minutes. During that time, the coach had regularly intervened by 
instructing the players what he wanted them to do, something common to every practice session observed. For example:

"Adam, you need to move further up the pitch"

After a series of these instructions had been given the coach stopped the entire practice.

\section{Coach: TOMMY JUST STOP AND COME OVER HERE}

Tommy instantly comes rushing over to where the coach is standing.

Player: > When your head is up $<$

Coach: When else? $\uparrow(1.8)$

Coach: Should I run with the ball now -

Coach: Should I run with it now -

Player: (.) ${ }^{\circ}$ No

Coach: Why (0.8)

Player: Because they are not looking $\downarrow$

Coach: > Okay, but why else wouldn’t I <

Player: It’s a tight angle (?)

Only Tommy is being asked these questions. While the coach speaks with him, five of the other players in the group are talking amongst themselves, with a group of three observing what is going on in sessions going on elsewhere. The remaining five players are listening in on the exchange between the coach and Tommy.

Coach: -Yes, but why else? (.)

Coach: - Have I got loads of space there (?) 
Cope et al.

428

429

430

431

432

433

434

435

436

437

438

439

442

443

444

445

446

447

448

449

450

451

452

453

454

455

Player: ${ }^{\circ}$ No

Coach: $=\{$ No, so I need more little touches which means I wouldn’t run so fast. If I am here now, have I got loads of space\}

Player: ${ }^{\circ}$ No

Coach: So do what instead then (1.0)

Player: Turn back and start again

Coach: So you need what to run with the ball ::

Player: Space $\uparrow$

Coach: > Good get back in there<

As Tommy quickly runs back to where he was originally standing, the coach asks him a final question.

Coach: TOMMY, DO YOU HAVE A BIG TOUCH OR SMALL TOUCH WHEN YOU HAVE LOTS OF SPACE (0.7) $\uparrow$

Player: BIG $\uparrow$

In the discussion of the previous theme is was demonstrated that players were involved in recitation rather than discussion, as the evaluation phase of CQPs was often brief or non-existent and the focus appeared on the coach leading the questioning. What also occurred was the sequential nature of question followed by response without the coach exploring players' answers further. For example, in this CQP, the coach asked a question ('When did I say we needed to run with the ball (2.1)'), which was followed by an instant response from a player ('> When your head is up <’), before the coach proceeded to ask a further question ('When else? $\uparrow$ (1.8)’), with out exploring the player's first response in any great depth. Mortimer and Scott (2003) argue being dialogic occurs when teachers engage with learners' ideas, expressed by a question and/or an answer and, consequently, stimulate the learners' intellect. A non-dialogic teacher-learner interaction occurs when the teacher does not explore the learners' idea or perspective and/or does not stimulate further reasoning to generate new meaning (Mortimer and Scott 2003). 
Cope et al.

In the present study coaches did not engage with the players and the questioning was non-dialogic in this sense - the CQPs appeared as an instrument for and of the coach, rather than being dialogic and using questions to explore players' concepts and promote interpretation of information (Pedrosa-de-Jesus and $\mathrm{Da}$ SilvaLopes 2011). The CA data showed how coaches' talk sometimes immediately followed that of the players, or overlapped that of the players or even themself in order to cut what players were saying. This occurred when players did not give a response that the coach wanted, as based on instructions given throughout practice, and so sought to ask another question, which would eventually lead to players providing the coach with the 'right' answer that the coach wanted to hear. Therefore, the coaches' low dialogic reaction formed part of their complementary pedagogic behaviour, illustrating that the quality of questioning involves creating a dialogic climate, and is not just about the frequency of questions asked (Harvey and Light 2015). Wright and Forrest (2007) suggest that learners' ability to discuss components of their performance most likely demonstrates their ability to successfully play the sport. It is of note that none of the CQPs led by the coaches in the present study encouraged players to discuss their responses with each other. Instead, coaches controlled the CQPs dictating when players could and could not speak.

\section{Discussion}

475 Coaching norms provide an overriding, powerful, and historical view of what coaches 476 should do and what coaching should look like (Cushion 2013; Cushion et al. 2003), 477 particularly in elite, or developmentally elite contexts (Potrac et al. 2007). One such norm suggests that the coach should be positioned as the authority and responsible for decision-making (Cushion 2013; Light and Evans 2010). The data in the present study like Groom et al. (2012) demonstrated that players were passive recipients who tended to intervene only when solicited by the coach and never on their own initiative.

482 The CQP illustrated an unequal encounter where players were not offered the 483 opportunity to decide when to speak and had to wait to be acknowledged. Hence coach-led and dominated encounters were evidenced, the coach acting overtly as the gatekeeper of knowledge in a didactic style that resulted in the coach not the players acting as adjudicator, and the coach playing a central role as the only authority of 487 learning - the coach as 'expert’ (Cushion 2013; Prain and Hickey 1995). The player’s 488 learning, skill acquisition, and understanding was through a coach-centred 
Cope et al.

489

490

491

492

493

494

495

496

497

498

499

500

501

502

503

504

505

506

507

508

509

510

511

512

513

514

515

516

517

518

transmission of subject-specific vocabulary, where the coaches mediated every exchange. Such an approach not only reinforces coaching norms but also is unlikely to encourage players to interpret or elaborate understanding or prompt deeper reflection and participation in learning (Cushion 2013; Prain and Hickey 1995).

The data showed that CQP occasionally resulted in questions directed to individuals but these questions were still asked in the presence of all players. While whole group questioning is important to allow reflection and hence meaning making (Light 2002) it is less significant in players understanding than inductive questions for individuals or small groups during practice (McNeill et al. 2008). A further issue with a whole group questioning approach reported from the CA data is that when questions were directed at certain players only, other players paid little attention. This can be seen in CQP three, where a group of players turned their attention to another coaches' practice while their CQP was taking place. Indeed, it is a false assumption that individual responses elicited from questions asked in whole-group settings reflect the depth of understanding across the group, while whole-group questioning is ineffective at instigating personal decision-making (Harvey and Light 2015; McNeill et al. 2008). To meet individual learner needs, it has been proposed that questions should be asked to individuals or smaller groups (Crowe and Standford 2010; McNeill et al. 2008). Curiously, while often advocated as 'player-centred', and appearing to emphasise the individual, questioning as evidenced in the present study was a 'one size fits all'. That is, regardless of individual learner differences, the same CQP with very little variation was deemed sufficient. However, not all learners are the same, nor are circumstances and contexts and advocating a singular whole group approach to questioning seems to contradict athlete centredness, and deny, or minimize, individual difference (Cushion 2013; Yang 2006). Seemingly positioned as active learners with different needs, learner subjectivity was, in fact, suppressed as the recipients of a universalised learning framework where decisions were made by the coach (Sicilia-Camacho and Brown 2008). CQP should reduce rather than maintain the power differential between player and coach through joint involvement in decision-making (Kidman 2005), yet CA data from this study would suggest the opposite occurred.

Given the link between coaching and learning conceptions, assumptions and presuppositions and adopted coaching practices, questioning practice can be a useful indicator of the main coaching and learning conceptions of a coach (Pedrosa-de-Jesus 
Cope et al.

522 and Da Silva Lopes 2011). Traditional coaching pedagogy has a number of

523 underlying assumptions that are framed by a positivistic paradigm underpinned by

524 behavioural conceptions of learning (Cushion 2013; Light 2008). This results in

525 coach-led and coach controlled practice sessions that are less dialogic, interactive and

526 one-directional, with the coach positioned as expert and athletes' passive receivers of

527 information (Cushion and Jones 2014; Potrac and Cassidy 2006). The presuppositions

528 in CQP discourse suggested that the coaches assumed that, as the expert, they must

529 emphasize skill acquisition and maintain close control of the discursive possibilities

530 of the session. Thus the coaches controlled the turn-taking contributions of the players

531 and ensured that a 'necessary' focused closed agenda was maintained - the coaches

532 agenda. This dominant discursive pattern served to establish, maintain and naturalize

533 the positions of power and authority for the coaches (Cushion and Jones 2014).

534 Interestingly, the coaches used 'we' during CQPs that appeared to imply a shared role

535 for the coach and players, however the coaches were the dominant agents and

536 authority for learning throughout (Cushion and Jones 2014; Prain and Hickey 1995).

537 A dominant coaching ideology appeared evident throughout CQP where the

538 coaches seemed to fail to recognise or understand the contradictions in conceptions of

539 coaching practice and athlete learning using questioning versus an authoritarian and

540 direct/behavioural approach (Cushion 2013; Light and Evans 2010). Several authors

541 coin this as coaches' ‘epistemological gap', the use of an approach but with limited

542 conceptual or practical understanding of it (Davis and Sumara 2003; Light 2008;

543 Partington and Cushion 2013). In uncritically accepting this ideology, coach's focus

544 little attention on how learners internalize their participation or the formation of long-

545 term knowledge, also overlooking the potential of language interactions as a resource

546 for learning (Prain and Hickey 1995).

547 Developments in youth coaching profess a deliberate shift from traditional 548 coach-led pedagogical modes to more non-didactic approaches including changes in 549 practice types and game forms. To this end, the governing body have introduced a 550 series of 'Youth Modules' with the purpose of developing coaches in a manner that 551 enables them to structure sessions where players are able to learn through trial and 552 error as coaches use a more questioning based approach; with 36,000 coaches 553 reported to have completed two out of the three part course. However, the present 554 study supports longitudinal research by Stodter and Cushion (2014) that these changes 
Cope et al.

555 are not being realized. Coaches are strongly committed to these innovations and 556 attempt to change coaching content and practice structures (Cushion 2013; Partington 557 and Cushion 2013; Stodter and Cushion 2014) but in reality the present study supports 558 Stodter and Cushion (2014) with the notion that 'deep structures of communication' 559 remain largely unaltered; with only make surface-level, if any, changes to their 560 coaching practice. A crucial issue in this respect is that coaching beliefs are stable 561 structures that are particularly difficult to change (Light and Evans 2013; Strean et al. 562 1997), and coaches come to value certain types of knowledge over others (Cushion et 563 al. 2003). Therefore, coaches appear unable to change discursive practices or 564 challenge ideologically driven coaching behaviours and attitudes.

\section{Conclusion}

566 The purpose of this study was to observe coaches during their daily coaching and 567 provide 'authentic' or 'real-life' questioning practices with the aim of analysing 568 qualitatively CQP and its wider discursive patterns. Data revealed that while coaches 569 engaged their players with a higher number of questions than reported in other studies many of these did not enable players to develop their critical thinking skills, or take

571 responsibility for their learning (Wright and Forrest 2007). So, while questioning has

572 been associated with an athlete-centred approach to coaching, deeper analysis shows 573 CQP's to be coach-led. In developing players a wide spectrum of questions and a 574 dialogical approach alongside complementary pedagogical behaviours is necessary to 575 challenge players knowledge, techniques, skills and strategies. If CQP is 'ineffective', 576 players lose out on abilities to 'defend, reflect on, examine or analyse their 577 performance' (Cleland and Pearse 1995, 33).

578 By using a CA approach to analyse data, we were able to move beyond 579 examining the type and frequency of questions asked by coaches to consider the 580 discursiveness of the interactions between coach and player(s). This showed how 581 coaches allowed players little time to consider a response to the question asked, and 582 when a response was not immediately given, coaches would re-phrase the question in 583 an attempt to lead players towards the answer, or answer the question themselves.

584 Where this happened, the result was an automatic response given by players as a 585 consequence of earlier instruction provided by the coach. Furthermore, coaches would 586 exercise their authority over their players by controlling the question/answer 
Cope et al.

587 exchange, and dictating when players were permitted to talk. While a CA approach 588 has enabled us to report the interactions that occur between coach and player, we 589 concur with Groom and colleagues that further work is needed in coaching to 590 understand this further.

591

592

593 
Cope et al.

References

595

596

597

598

599

600

601

602

603

604

605

606

607

608

609

610

611

612

613

614

615

616

617

618

619

620

621

622

623

624

625

626

627

628

629

630

631

632

633

634

635

636

637

638

639

640

641

Becker, A., 2009. "It's not what they do, it's how they do it: Athlete experiences of great coaching”. International Journal of Sports Science and Coaching, 4 (1), 93-119.

Becker, A.J. and Wrisberg, C.A., 2008. "Effective coaching in action: Observations of legendary collegiate basketball coach Pat Summitt”. Sport Psychologist, 22 (2), 197-211.

Brewer, C.J. and Jones, R.L., 2002. “A five-stage process for establishing contextually valid systematic observation instruments: the case of rugby union”. Sport Psychologist, 16 (2), 138-159.

Butler, J.I., 2005., "TGfU pet-agogy: old dogs, new tricks and puppy school”. Physical Education and Sport Pedagogy, 10 (3), 225-240.

Carson, F., 2008. "Utilizing video to facilitate reflective practice: Developing sports coaches”. International Journal of Sports Science and Coaching, 3 (3), 381390.

Cassidy, T, Jones, R., and Potrac, P., 2009. Understanding Sports Coaching: the social, cultural and pedagogical foundations of coaching practice. $2^{\text {nd }}$ ed. London: Routledge.

Cazden, C.B., 2001. Classroom discourse: the language of teaching and learning. $2^{\text {nd }}$ ed. Portsmouth, NH: Heinemann.

Chambers, K.L. and Vickers, J.N., 2006. "Effects of bandwidth feedback and questioning on the performance of competitive swimmers". Sport Psychologist, 20 (2), 184.

Cleland, F. and Pearse, C., 1995. "Critical thinking in elementary physical education: reflections on a yearlong study". Journal of Physical Education, Recreation, and Dance, 66 (6), 31-38.

Crowe, M., and Stanford, P., 2010. "Questioning for quality”. Delta Kappa Gamma Bulletin, 76 (4), 36-44.

Crum, B.J., 1993. "Conventional thought and practice in physical education: Problems of teaching and implications for change”. Quest 45 (3): 339-356.

Cushion, C.J., 2013. "Applying Game Centered Approaches in coaching: a critical analysis of the 'dilemmas of practice' impacting change". Sports Coaching Review, 2 (1), 61-76.

Cushion, C.J., Armour, K.M. and Jones, R.L., 2003. "Coach education and continuing professional development: Experience and learning to coach”. Quest, 55 (3), 215-230.

Cushion, C., Ford, P.R. and Williams, M.A., 2012. "Coach behaviours and practice structures in youth soccer: Implications for talent development”. Journal of Sports Sciences, 30, 1631-1641.

Cushion, C.J. and Jones, R.L., 2001. "A systematic observation of professional toplevel youth soccer coaches”. Journal of Sport Behavior, 24 (4), 354-376.

Cushion, C. and Jones, R.L., 2006. "Power, discourse, and symbolic violence in professional youth soccer: The case of Albion Football Club". Sociology of Sport Journal 23, (2), 142-161.

Cushion, C.J. and Jones, R.L., 2014. “A Bourdieusian analysis of cultural reproduction: Socialisation and the 'hidden curriculum' in professional football”. Sport, Education and Society, 19 (3), 276-298.

Cushion, C. and Partington, M., 2014. "A critical analysis of the conceptualisation of 
Cope et al. 'coaching philosophy’”. Sport, Education and Society, DOI: 10.1080/13573322.2014.958817

Daniel, M.-F. and Bergman-Drewe, S., 1998. "Higher-Order Thinking, Philosophy, and Teacher Education in Physical Education”. Quest, 50 (1), 33-58.

Davis, B. and Sumara, D., 2003. "Why aren't they getting this? Working through the regressive myths of constructivist pedagogy". Teaching Education, 14, 123140.

Ennis, C.D. 1994., "Knowledge and beliefs underlying curricular expertise”. Quest, 46 (2), 164-175.

Forrest, G., 2014. "Questions and answers: understanding the connection between questioning and knowledge in game-centred approaches”. In: R. Light, J. Quay, S. Harvey, and A. Mooney, eds. Contemporary developments in games teaching. London: Routledge. pp. 167-177.

Gréhaigne, J.-F., Richard, J.-F., and Griffin, L.L., 2005. Teaching and learning team sports and games. New York, NY: Routledge Falmer.

Groom, R., Cushion, C.J. and Nelson, L.J., 2012. "Analysing coach-athlete 'talk in interaction' within the delivery of video-based performance feedback in elite youth soccer”. Qualitative research in sport, exercise and health, 4 (3), 439458.

Groom, R., Nelson, L., Potrac, P., and Cushion, C., 2014. “Conversational analysis”. In: L. Nelson, R. Groom, and P. Potrac, eds. Research Methods in Sports Coaching. London: Routledge. pp. 227-238

Harvey, S., Cushion, C.J and Massa-Gonzalez, A-N., 2010. "Learning a new method: Teaching Games for Understanding in the coaches’ eyes”. Physical Education and Sport Pedagogy, 15 (4), 361-382.

Harvey, S., Cushion, C., Cope, E. and Muir, B., 2013. “A season long investigation into coaching behaviours as a function of practice state: The case of three collegiate coaches". Sports Coaching Review, 2, 13-32.

Harvey, S., Cushion, C. and Salmon, P., 2015. "Dilemmas faced by pre-service teachers when learning about and implementing a game-centred approach”. European Physical Education Review, 21 (2), 238-256.

Harvey, S. and Light, R.L., 2015. Questioning for learning in game-based approaches to teaching and coaching. Asia Pacific Journal of Health, Sport and Physical Education, 6 (2), 1-36.

Hastie, P., and Hay, P., 2012. “Qualitative approaches”. In: K. Armour, and D. MacDonald, eds. Research methods in physical education and youth sport. London: Routledge. pp. 79-94

Hepburn, A., and G. B. Bolden. 2013. “The conversation analytic approach to transcription”. In: J. Sidnell, and T. Stivers, eds. The handbook of conversation analysis. Wiley-Blackwell: London. pp. 57-76.

Jones, R. L., 2009. "Coaching as caring (the smiling gallery): Accessing hidden knowledge”. Physical education and sport pedagogy, 14 (4), 377-390.

Kidman, L., 2005. Athlete-centred coaching: Developing inspired and inspiring people. Christchurch, NZ: IPC Print Resources.

Light, R., 2002. "Engaging the body in learning: promoting cognition in games through TGfU”. ACHPER Healthy Lifestyles Journal, 49 (2), 23-26.

Light, R., 2008. "Complex learning theory in physical education: An examination of its epistemology and assumptions about how we learn”. Journal of Teaching in Physical Education, 27 (1), 21-37.

Light, R.L. and Evans, J.R., 2010. “The impact of game sense pedagogy on Australian 
Cope et al.

692

693

694

695

696

697

698

699

700

701

702

703

704

705

706

707

708

709

710

711

712

713

714

715

716

717

718

719

720

721

722

723

724

725

726

727

728

729

730

731

732 rugby coaches' practice: A question of pedagogy”. Physical Education and Sport Pedagogy, 15 (2), 103-115.

Light, R.L. and Evans, J.R., 2013. "Dispositions of elite-level Australian rugby coaches towards game sense: characteristics of their coaching habitus". Sport, Education and Society, 18 (3), 407-423.

McNeill, M.C., Fry, J.M., Wright, S.C., Tan, C.W.K. and Rossi, T., 2008. "Structuring time and questioning to achieve tactical awareness in games lessons”. Physical Education and Sport Pedagogy, 13, 231-249.

Metzler, M.W., 2000. Instructional models for physical education. $2^{\text {nd }}$ ed. Boston, MA, Allyn \& Bacon.

Miles, M. B., and Huberman. A.M., 1994. Qualitative data analysis: An extended sourcebook. $2^{\text {nd }}$ ed. Thousand Oaks, CA: Sage.

Mondada, L., 2013. "The conversation analytic approach to data collection”. In: J. Sidnell. and T. Stivers, eds. The handbook of conversation analysis. WileyBlackwell: London. pp. 32-56.

Mortimer, E., and Scott, P., 2003. Meaning Making In Secondary Science Classrooms. London: McGraw-Hill Education.

Oosterheert, I.E. and Vermunt, J.D., 2001. "Individual differences in learning to teach: Relating cognition, regulation and affect”. Learning and Instruction, 11 (2), 133-156.

Pagliaro, M.M., 2011. Exemplary Classroom Questioning: Practices to Promote Thinking and Learning. New York, NY: Rowman and Littlefield Education.

Partington, M. and Cushion, C., 2013. "An investigation of the practice activities and coaching behaviors of professional top- level youth soccer coaches". Scandinavian Journal of Medicine \& Science in Sports, 23 (3), 374-382.

Patton, M.Q. 2002., "Two decades of developments in qualitative inquiry a personal, experiential perspective”. Qualitative Social Work, 1 (3), 261-283.

Pedrosa-de-Jesus, M. H. and da Silva Lopes, B., 2011. "The relationship between teaching and learning conceptions, preferred teaching approaches and questioning practices”. Research papers in Education, 26 (2), 223-243.

Potrac, P. and Cassidy, T., 2006. "The coach as 'a more capable other”. In: R. L. Jones, ed. The sports coach as educator: Reconceptualising sports coaching. London: Routledge. pp. 39-50

Potrac, P., Jones, R. and Cushion, C., 2007. “Understanding power and the coach's role in professional English soccer: A preliminary investigation of coach behaviour". Soccer and Society, 8 (1), 33-49.

Prain, V. and Hickey. C., 1995. "Using discourse analysis to change physical Education”. Quest, 47, 76-90.

Sicilia-Camacho, A. and Brown, D., 2008. "Revisiting the paradigm shift from the versus to the non-versus notion of Mosston's Spectrum of teaching styles in physical education pedagogy: a critical pedagogical perspective”. Physical Education and Sport Pedagogy, 13 (1), 85-108.

Siedentop, D., and Tannehill, D., 2000. Developing teaching skills in physical education. 4th ed. Mountain View, CA: Mayfleld.

Sparkes, A.C. 1990. Curriculum change and physical education: towards a micropolitical understanding. Deakin University.

Stodter, A. and Cushion, C.J., 2014. "Coaches' learning and education: a case study of cultures in conflict”. Sports Coaching Review, 3 (1), 63-79.

Strean, W.B., Senecal, K.L., Howlett, S.G. and Burgess, J.M., 1997. "Xs and Os and what the coach knows: improving team strategy through critical thinking”. 
Cope et al.

Thompson, C. L. and Zeuli, J.S., 1999. The frame and the tapestry: Standards-based reform and professional development. In: L. Darling-Hammond, and G. Sykes, eds. Teaching as the learning profession: Handbook of policy and practice, edited by. San Francisco, CA: Jossey Bass. pp. 341-375

The Premier League., 2011. Elite Player Performance Plan. London: The Premier League.

Tinning, R.I., 1988. "Student Teaching and the Pedagogy of Necessity". Journal of Teaching in Physical Education, 7 (2), 82-89.

Wiersema, J.A. and Licklider, B.L., 2009. "Intentional Mental Processing: Student Thinking as a Habit of Mind”. Journal of Ethnographic and Qualitative Research, 3 (2), 117-127.

Wright, J. and Forrest, G., 2007. “A social semiotic analysis of knowledge construction and games centred approaches to teaching”. Physical Education and Sport Pedagogy, 12 (3), 273-287.

Yang, M. 2006., "A critical review of research on questioning in education: limitations of its positivistic basis”. Asia Pacific Education Review, 7 (2), 195204. 